\title{
Garage Location Selection for Public Transportation System in Istanbul: An Integrated Fuzzy AHP and Fuzzy Axiomatic Design Based Approach
}

\author{
Özge Nalan Bilişik, Nurgül Demirtaş, Umut Rıfat Tuzkaya, and Hayri Baraçlı \\ Department of Industrial Engineering, Yildiz Technical University, Besiktas, 34349 Istanbul, Turkey \\ Correspondence should be addressed to Umut Rifat Tuzkaya; tuzkaya@yildiz.edu.tr
}

Received 12 May 2014; Revised 6 August 2014; Accepted 20 August 2014; Published 14 September 2014

Academic Editor: Xinkai Chen

Copyright ( 2014 Özge Nalan Bilişik et al. This is an open access article distributed under the Creative Commons Attribution License, which permits unrestricted use, distribution, and reproduction in any medium, provided the original work is properly cited.

\begin{abstract}
We try to determine the best location for a bus garage, in which maintenance and repair activities are operated, for public transportation system in Istanbul. An integrated multicriteria decision making technique (MCDM) is used to obtain reliable results. Firstly, various criteria related to garage location selection are specified and weighted by fuzzy AHP (analytical hierarchy process). Then, these weights are used in fuzzy axiomatic design (AD) technique to determine the precedencies of the alternative garage locations.
\end{abstract}

\section{Introduction}

With the increase of the living standards in Istanbul, the population is asking for a higher service and quality. This requirement is also including the quality of the public transportation system. Istanbul Electricity, Tramway and Tunnel (IETT) General Management, which carries a huge part of the passenger density as a public transportation corporation, is the most important actor in Istanbul traffic. Serving in high quality is very difficult in Istanbul, when the constraints are considered, like road conditions, number of vehicles, and high density of the passengers especially in the peak hours. The number of the buses is increasing day by day in proportion to the population of the city. Besides, this increase brings extra problems caused by the ages of the buses, accidents in the traffic, lack of the road infrastructures, and overusing the buses. Maintenance activities, especially, have a vital importance on journeys to eliminate these problems and to ensure customer satisfaction without failures.

The difficulties in Istanbul for effective public transportation are rapid and unplanned public development, historical settlement texture, population, rapid increase in vehicle and transportation requirements, and geographical features (rough topography, Bosphorus and The Golden Horn). As an indicator, there are 13,532,745 average passengers in public transportation system of Istanbul and 2,039,837 of them use IETT. This is a very high number when it is compared with the world average. IETT carries passengers with a 334 bus fleet in bus rapid transit (BRT) system and with 2,279 buses in other lines.

In bus garages, the repair and maintenance activities and corrective and preventive actions are done. There are nine garages in IETT and the number of busses and the spaces are shown in Table 1.

As a result of the traffic congestion and the number of travels in a day, lots of breakdowns and the maintenance requirements occur and the failure frequency increases in Istanbul. The maintained bus numbers per day within IETT are shown in Table 2.

In this study, we try to determine the best locations for bus garages to operate the maintenance and repair activities. There are many important criteria that affect the location decisions, like cost, time, infrastructure, environment, accessibility, other macro factors, and so forth. Istanbul is a growing city and the land use is very important in terms of the city master plans. Therefore, probable places for bus garages are determined by the IETT authorities and best alternative is selected considering the above-mentioned criteria. These 
TABLE 1: Specifications of garages [5].

\begin{tabular}{lccc}
\hline Garage & $\begin{array}{c}\text { Number of } \\
\text { buses per garage }\end{array}$ & $\begin{array}{c}\text { Total space } \\
\left(\mathrm{m}^{2}\right)\end{array}$ & $\begin{array}{c}\text { Indoor space } \\
\left(\mathrm{m}^{2}\right)\end{array}$ \\
\hline İkitelli & 528 & 192,000 & 28,000 \\
Anadolu & 404 & 58,200 & 10,000 \\
Topkap1 & 125 & 17,588 & 7,100 \\
Edirnekap1 & 400 & 60,000 & 6,720 \\
Ayazağa & 314 & 102,275 & 11,500 \\
Hasanpaşa & 368 & 37,000 & 4,000 \\
Kağıthane & 220 & 65,000 & 7,920 \\
Beykoz & 147 & 13,000 & 2,300 \\
Şahinkaya & 137 & 15,000 & 1,420 \\
Sarıgazi & 2,619 & 560,063 & 78,960 \\
\hline Total & & & \\
\hline
\end{tabular}

TABLE 2: Maintained bus number per day.

\begin{tabular}{lc}
\hline Year & $\begin{array}{c}\text { Maintained bus number } \\
\text { (daily average) }\end{array}$ \\
\hline 2011 & 33 \\
2010 & 35 \\
2009 & 35 \\
2008 & 37 \\
2007 & 47 \\
\hline
\end{tabular}

* The data has been collected from the annual reports that are published on IETT website.

criteria are constituted considering EN 13816 standards which try to promote a quality transport operations and focus interest on customers' needs and expectations [4].

An integrated MCDM technique, fuzzy AHP and fuzzy $\mathrm{AD}$, is used for this purpose. Fuzzy AHP is used to weight the criteria according to the precise and imprecise judgments of the decision makers. Then the obtained weights of the criteria are utilized as an input data in fuzzy AD to determine the precedencies of the alternative locations.

\section{Literature Review}

In this study, the axiomatic design method is used to solve the garage location selection problem for Istanbul. The linguistic expressions of experts are taken into consideration and the criteria weights are calculated by using Buckley's fuzzy AHP method. In this section, the literature review about axiomatic design applications integrated with other MCDM methods, location selection studies, and group decision making (GDM) applications are presented.

In the last ten years, especially, $\mathrm{AD}$ has a chance to be applied in many different fields and it is continuously improving with the addition of new developments. So far, $\mathrm{AD}$ has found a chance to be used in a wide range [6]. It is used for the design of software systems [7], quality design [8], manufacturing systems [9], flexible manufacturing systems [10], cellular manufacturing systems [11], and equipment selection [12].

Reference [13] suggests fuzzy MCDM methodologies for selection among renewable energy alternatives. The author use fuzzy AHP to evaluate the experts' scores and fuzzy AD to evaluate the alternatives under objective or subjective criteria with respect to the functional requirements obtained from experts. Reference [14] aims to propose an environmental impact assessment methodology based on an integrated fuzzy AHP-ELECTRE (Elimination and Choice Translating Reality English) approach in the context of urban industrial planning. Reference [15] proposes a hybrid approach on ensuring the competitiveness requirements for major Turkish container ports by utilizing fuzzy $\mathrm{AD}$ and fuzzy technique for order performance by similarity to ideal solution (TOPSIS) methodologies to manage strategic decision making with incomplete information. Reference [1] discusses supplier selection problem for a white goods manufacturer and $\mathrm{AD}$ method is proposed for the solution of the problem. Reference [16] develops a decision support system (DSS) based on fuzzy information axiom (FIA) in order to make decision procedure easy. Reference [17] investigates a systematic evaluation model on docking facilities of shipyards to provide a decision aid for technical ship managers and to perform this responsibility in an efficient manner and fuzzy AD approach is used for selection among shipyards. Reference [3] realizes the selection of the best company under determined criteria using both multiattribute $\mathrm{AD}$ and AHP. The fuzzy multiattribute AD approach is also developed and it is compared by one of the fuzzy AHP methods in the literature. Reference [18] compares AHP, TOPSIS, ELECTRE, and Grey Theory methodologies in terms of main characteristic of decision theory and thus advantages and disadvantages of these methodologies are offered. Then these methodologies are used on warehouse selection problem. Reference [19] presents an application of fuzzy TOPSIS that is one of the MCDM approaches for location planning for urban distribution centers under uncertainty. Reference [20] proposes a comprehensive methodology for the selection of logistic center location. The proposed methodology consists of axiomatic fuzzy set clustering method to effectively evaluate logistics center location and TOPSIS-based final selection. Reference [21] aims to develop a conceptual model 10 based on a combination of the fuzzy AHP and artificial neural networks (ANN) methods in the process of decision making in order to select the most appropriate location. Reference [22] proposes a new hybrid method combining the concepts of fuzzy DEMATEL and a new method of fuzzy MCDM in a fuzzy environment to solve the problems of international distribution center location selection. Reference [23] studies a garage location selection problem for a firm in urban passenger transport sector in Istanbul. When the problem is investigated, it will be noticed that there are lots of criteria that must be taken into account to minimize the dead kilometers. Hence, firstly, the criteria are determined and then the problem is solved using MCDM techniques.

Reference [24] presents a new fuzzy multiple attributes decision making (FMADM) approach. The proposed system integrates fuzzy set theory, the factor rating system, and simple additive weighting to evaluate facility location alternatives. Reference [25] aims to solve facility location problems using different solution approaches of fuzzy multiattribute GDM. The paper includes four different fuzzy multiattribute 
GDM approaches. These approaches are extended to select the best facility location alternative by taking into account quantitative and qualitative criteria. A short comparative analysis among the approaches and a numeric example to each approach are given. Reference [26] established a fuzzy MCGDM model that aggregates both subjective and objective information under multilevel hierarchies of criteria. They try to increase the level of overall satisfaction for the final decision across the group and deal with uncertainty in decision process. A fuzzy MCGDM decision support system (called Decider) is developed, which can handle information expressed in linguistic terms to assess and rank a set of alternatives within a group of decision makers. Reference [27] proposes an integrated fuzzy GDM method in order to deal with the fuzziness of preference of decision makers. This method allows group members to express fuzzy preferences for alternatives and individual judgments for solution selection criteria to decide the weights of group members. And [28] focuses on long-term load forecasting for Taiwan case by using collaborative fuzzy-neural approach. Multiple experts construct their own fuzzy back propagation networks from various viewpoints to forecast the long-term load in a country. Then, the fuzzy intersection is applied to aggregate these long-term load forecasts.

The literature includes many MCDM techniques integrations for various areas as mentioned above. Reference [23] also studied the bus garage location selection but the selection is realized by combining fuzzy AHP and PROMETHEE techniques in this study. Even though fuzzy AHP and fuzzy $\mathrm{AD}$ techniques are combined for solving the decision making problems of the different areas, they are not used in a garage location selection problem according to our literature research. Also, it is difficult to come across with a decision support system for a garage location selection among the city logistics and public transportation studies. The novelty of this study is not only applying this integrated methodology to a garage location selection as an unstudied area, but also bringing numerous criteria together to realize a comprehensive evaluation for public transportation system. Furthermore proposed method can be used as a decision support system by the local authorities and the other decision makers who are not familiar with these decision making methods, since the ADSolver software is developed by the authors with a userfriendly interface. It makes all the mathematical calculations of solution process easy.

\section{Methodology}

3.1. Problem Definition. In this study, the most appropriate garage location selection problem for IETT is investigated and a methodology is developed to solve it. The steps of this methodology are shown in Figure 1 and the used techniques are explained in the following subsections.

3.2. Techniques. In the proposed methodology, fuzzy AHP is used to determine the criteria weights and crisp axiomatic design, fuzzy axiomatic design, and weighted fuzzy axiomatic design are used to select the most appropriate garage location.
3.2.1. Fuzzy AHP. Defining the complex and hard situations is very difficult with numerical expressions, so linguistic variables have to be used in such situations. The linguistic variables are words/sentences in languages.

To deal with vagueness of human thought, the fuzzy set theory is introduced by Zadeh which was oriented to the rationality of uncertainty due to imprecision or vagueness. A major contribution of fuzzy set theory is its capability of representing vague data. The theory also allows applying of mathematical operators and programming to the fuzzy domain. A fuzzy set is a class of objects with a continuum of grades of membership. Such a set is characterized by a membership (characteristic) function, which assigns to each object a grade of membership ranging between zero and one [29].

In our study, Buckley's Fuzzy AHP methodology is used to fuzzify the hierarchical analysis by allowing fuzzy numbers for the pairwise comparisons and find the weights of all criteria. In the following the fuzzy AHP steps are explained [30].

Step 1. Construct pairwise comparison matrices among all the elements/criteria in the dimensions of the hierarchy system. Assign linguistic terms to the pairwise comparisons by asking which is the more important of each two elements/criteria.

Step 2. Use geometric mean technique to define the fuzzy geometric mean and fuzzy weights of each criterion by Buckley as follows:

$$
\begin{aligned}
\widetilde{r}_{i} & =\left(\widetilde{a}_{i 1} \otimes \widetilde{a}_{12} \otimes \cdots \otimes \widetilde{a}_{i n}\right)^{1 / n}, \\
\widetilde{w}_{i} & =\widetilde{r}_{i} \otimes\left(\widetilde{r}_{1} \oplus \cdots \oplus \widetilde{r}_{n}\right)^{-1},
\end{aligned}
$$

where $\widetilde{a}_{i n}$ is fuzzy comparison value of criterion $i$ to criterion $n$; thus, $\widetilde{r}_{i}$ is geometric mean of fuzzy comparison value of criterion $i$ to each criterion, and $\widetilde{w}_{i}$ is the fuzzy weight of the $i$ th criterion and can be indicated by a TFN, $\widetilde{w}_{i}=\left(L w_{i}, M w_{i}, U w_{i}\right)$. Here $L w_{i}, M w_{i}$, and $U w_{i}$ stand for the lower, middle, and upper values of the fuzzy weight of the $i$ th criterion.

Step 3. Take $\widetilde{E}_{i j}^{k}$ to indicate the fuzzy performance value of evaluator $k$ towards alternative $i$ under criterion $j$, and all of the evaluation criteria will be indicated by $\widetilde{E}_{i j}^{k}=$ $\left(L E_{i j}^{k}, M E_{i j}^{k}, U E_{i j}^{k}\right)$ :

$$
\widetilde{E}_{i j}=\left(\frac{1}{m}\right) \otimes\left(\widetilde{E}_{i j}^{1} \oplus \widetilde{E}_{i j}^{2} \oplus \cdots \oplus \widetilde{E}_{i j}^{m}\right) .
$$

The end-point values $L E_{i j}, M E_{i j}$, and $U E_{i j}$ can be solved by the method put forward by Buckley; that is,

$$
\begin{gathered}
L E_{i j}=\frac{\left(\sum_{k=1}^{m} L E_{i j}^{k}\right)}{m} ; \quad M E_{i j}=\frac{\left(\sum_{k=1}^{m} M E_{i j}^{k}\right)}{m} ; \\
U E_{i j}=\frac{\left(\sum_{k=1}^{m} U E_{i j}^{k}\right)}{m} .
\end{gathered}
$$




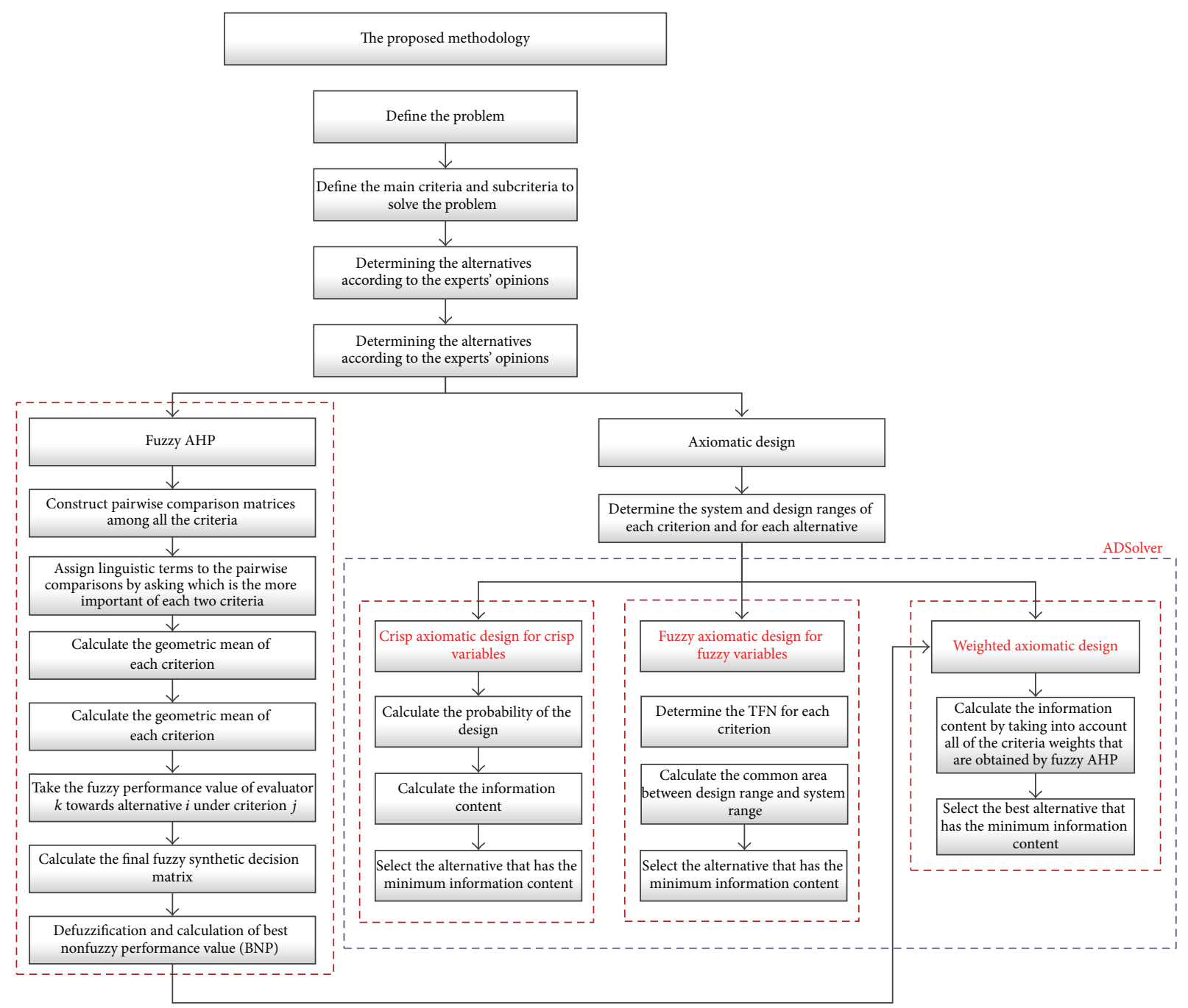

FIGURE 1: The proposed methodology.

Step 4. The criteria weight vector $\widetilde{w}=\left(\widetilde{w}_{1}, \ldots, \widetilde{w}_{j}, \ldots, \widetilde{w}_{n}\right)^{t}$; the fuzzy performance matrix of each of the alternatives $\widetilde{E}=$ $\left(\widetilde{E}_{i j}\right)$. The final fuzzy synthetic decision matrix $\widetilde{R}=\widetilde{E} \circ \widetilde{w}$.

$\widetilde{R}_{i}=\left(L R_{i}, M R_{i}, U R_{i}\right)$, where $L R_{i}, M R_{i}$, and $U R_{i}$ are the lower, middle, and upper synthetic performance values of the alternative $i$; that is,

$$
\begin{gathered}
L R_{i}=\sum_{j=1}^{n} L E_{i j} \times L w_{j} ; \quad M R_{i}=\sum_{j=1}^{n} M E_{i j} \times M w_{j} ; \\
U R_{i}=\sum_{j=1}^{n} U E_{i j} \times U w_{j} .
\end{gathered}
$$

Step 5. The procedure of defuzzification is to locate the best nonfuzzy performance value (BNP). Utilize the COA (center of area) method to find out that the BNP is a simple and practical method, and there is no need to bring in the preferences of any evaluators, so it is used in this study. The
BNP value of the fuzzy number $\widetilde{R}_{i}$ can be found by the following equation:

$$
\mathrm{BNP}_{i}=\frac{\left[\left(U R_{i}-L R_{i}\right)+\left(M R_{i}-L R_{i}\right)\right]}{3}+L R_{i}, \quad \forall i .
$$

3.2.2. Axiomatic Design (AD). $\mathrm{AD}$ has been put forward as a "scientific design approach" since the early 1980s. However, it started to be used in various areas as a method of design engineering intensively after the issue of the book which has been written by E. Yilmaz, 2006 [6].

In our study, crisp $\mathrm{AD}$ is used for crisp criteria, fuzzy $\mathrm{AD}$ is used for fuzzy criteria, and the weighted fuzzy AD is used to take into account the different weights of each criterion.

Crisp AD. $\mathrm{AD}$ is proposed to compose a scientific and systematic basis that provides structure to design process for engineers. The primarily goal of $\mathrm{AD}$ is to provide a thinking process to create a new design and/or to improve the existing design. To improve a design, the axiomatic approach uses 


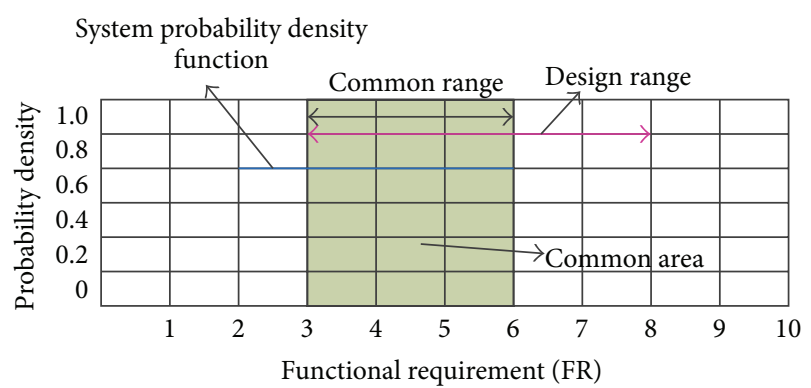

FIGURE 2: Design range, system range, common range, and PDF of a FR [1].

two axioms named "independence axiom" and "information axiom."

Independence axiom states that the independence of functional requirements (FRs) must always be maintained, where FRs are defined as the minimum set of independent requirements that characterize the design goals. Then, information axiom states that the design having the smallest information content is the best design among those designs that satisfy the independence axiom [16].

The information axiom is a conventional method and facilitates the selection of proper alternative. In other words, information axiom helps the independence axiom to put forward the best design. The information axiom is symbolized by the information content that is related to the probability of satisfying the design goals. The information content $(I)$ is given by

$$
I_{i}=\log _{2} \frac{1}{p_{i}},
$$

where $p_{i}$ is the probability of achieving a given FR [16].

In any design situation, the probability of success is given by what designer wishes to achieve in terms of tolerance (i.e., design range) and what the system is capable of delivering (i.e., system range). As shown in Figure 2, the overlap between the designer-specified "design range" and the system capability range "system range" is the region where the acceptable solution exists. Therefore, in the case of uniform probability, distribution function $p_{i}$ may be written as [31]

$$
p_{i}=\left(\frac{\text { common range }}{\text { system range }}\right) .
$$

So, the information content is equal to

$$
I_{i}=\log _{2}\left(\frac{\text { system range }}{\text { common range }}\right) \text {. }
$$

The probability of achieving $\mathrm{FR}_{i}$ in the design range may be expressed, if $\mathrm{FR}_{i}$ is a continuous random variable, as [31]

$$
p_{i}=\int_{d r_{i}}^{d r^{u}} p_{s}\left(\mathrm{FR}_{i}\right) d \mathrm{FR}_{i}
$$

where $p_{s}\left(\mathrm{FR}_{i}\right)$ is the system pdf (probability density function) for $\mathrm{FR}_{i}$. Equation (9) gives the probability of success by

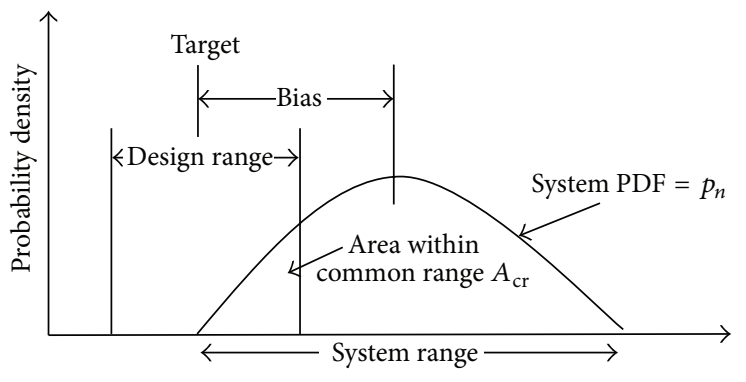

FIgURE 3: The probability of success for a one-FR, one-DP design [2].

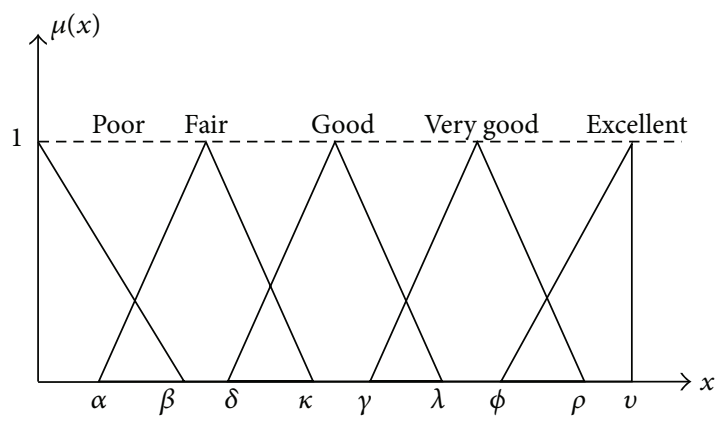

FIgURE 4: Triangular fuzzy numbers [3].

integrating the system pdf over the entire design. In Figure 3, the area of the common range $\left(A_{\mathrm{cr}}\right)$ is equal to the probability of success $p_{i}$. Therefore, the information content is equal to [31]

$$
I_{i}=\log _{2}\left(\frac{1}{A_{\mathrm{cr}}}\right)
$$

Fuzzy AD. MCDM techniques in the literature are solutions when data is not crisp. In addition, fuzzy multiple criteria AD approach can be used when data is not crisp [1].

The fuzzy data can be linguistic terms, fuzzy sets, or fuzzy numbers. If the fuzzy data are linguistic terms, they are transformed into fuzzy numbers first. Then all the fuzzy numbers (or fuzzy sets) are assigned crisp scores. The following numerical approximation systems are proposed to systematically convert linguistic terms to their corresponding fuzzy numbers. The system contains five conversion scales as in Figure 4 [3].

In the fuzzy case, we have incomplete information about the system and design ranges. The system and design range for a certain criterion will be expressed by using "over a number," "around a number," or "between two numbers." Triangular or trapezoidal fuzzy numbers can represent these kinds of expressions. We now have a membership function of triangular or trapezoidal fuzzy number whereas we have a probability density function in the crisp case. So, the common area is the intersection area of triangular or trapezoidal 


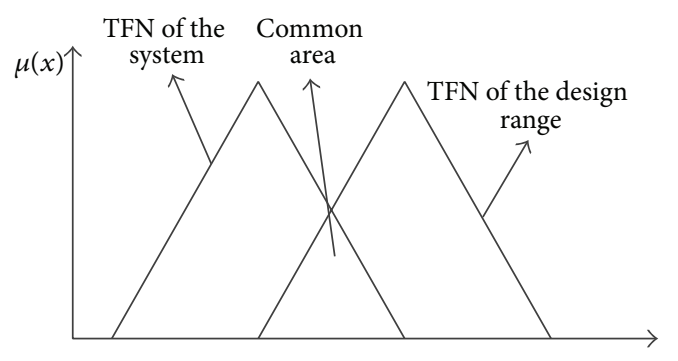

FIGURE 5: Common area of system and design range [3]

fuzzy numbers. The common area between design range and system range is shown in Figure 5 [3]:

$$
I=\log _{2}\left(\frac{\text { TFN of System Design }}{\text { Common Area }}\right) .
$$

Weighted Fuzzy AD. In the method in Section 4.2, the weights for all subcriteria are equal. If the decision maker wants to assign a different weight $\left(w_{j}\right)$ for each criterion, the following weighted multiattribute $\mathrm{AD}$ approach can be used.

The following is proposed for the weighted multiattribute $\mathrm{AD}$ approach:

$$
\begin{gathered}
{\left[\log _{2}\left(\frac{1}{p_{i j}}\right)\right]^{1 / w_{j}}, \quad 0 \leq I_{i j} \leq 1,} \\
{\left[\log _{2}\left(\frac{1}{p_{i j}}\right)\right]^{w_{j}}, \quad I_{i j} \geq 1,} \\
w_{j}, \quad I_{i j}=1,
\end{gathered}
$$

where $I_{i j}$ is the information content of the alternative $i$ for the criterion $j ; w_{j}$ the weight of the criterion $j ; p_{i j}$ is the probability of achieving the functional requirement $\mathrm{FR}_{j}$ (criterion $j$ ) for the alternative $i$ [32].

The strength of the proposed method over the existing methods can be explained as follows. AD approach takes into account the design range of each criterion determined by the designer. Thus, the alternative providing the design ranges is selected in $\mathrm{AD}$ approach while the alternative meeting the criteria at their best levels is selected in many other methods.

For example, if the designer wants to satisfy the criterion called "technological infrastructure" in the determined design range by himself/herself, he/she can use $\mathrm{AD}$ approach. The designer may not want to meet this criterion at its best level because of its cost. This opportunity is not possible when most of the other existing methods such as AHP, fuzzy AHP, and scoring models are used. The AD approach also differs from many other existing methods from the point of the rejection of an alternative when it does not meet the design range of any criterion. However, the decision maker can assign a numerical value instead of "infinitive" in order to make the selection of an alternative which meets all other criteria successfully possible, except the criterion having an "infinitive" value [12].

\section{Application}

In this study we try to select the most appropriate garage location in Istanbul. The fuzzy $\mathrm{AD}$ and weighted fuzzy $\mathrm{AD}$ which is weighted by fuzzy AHP are used for the evaluation. Then the results of both methods are compared. The methodology is applied for garage location selection in both of European Side and Asian Side of Istanbul separately. The alternative garage locations and the evaluation criteria are identified according to the experts' opinions in IETT.

The alternative areas that are proposed by experts are Beylikdüzü, Arnavutköy, and Silivri in the European Side and Pendik, Sultanbeyli, and Tuzla in Asian Side of Istanbul. The number of main-criteria that we use to solve the problem is six and the number of subcriteria is eighteen. The descriptions of criteria are shown in Table 3.

Firstly we determine the weights of main and subcriteria by using the Buckley's fuzzy AHP methodology. In the first stage of this methodology, the pairwise comparisons of main and subcriteria are made by experts. The pairwise comparison matrix of main criteria is shown in Table 4. After main criteria comparisons, subcriteria comparisons are made and the weights of all criteria are calculated. The results are shown in Table 5.

After determining the weights of the criteria, we apply the $\mathrm{AD}$ manually to find final decision. We use crisp $\mathrm{AD}$ for the "Cost" main criterion and fuzzy AD for other main criteria.

The system and design range are identified by experts in IETT to implement the AD methodology for European and Asian Side of Istanbul as shown in Tables 6 and 7, respectively.

In the first stage of $\mathrm{AD}$, we make the calculations without the criteria weights. The triangular fuzzy numbers for intangible factors are excellent $(16,20,20)$, very $\operatorname{good}(12,15,18)$, good $(8,11,14)$, fair $(4,7,10)$, and poor $(0,0,6)$. The results of unweighted fuzzy axiomatic design (Tables 8 and 9) show that the alternative "Arnavutköy" for the European Side of Istanbul and the alternative "Sultanbeyli" for the Asian Side of Istanbul are selected as the new garage locations because they have the minimum information contents.

Experts examined that weights of criteria are not equal, so that weighted $\mathrm{AD}$ is used to find out realistic result. In the second stage, weighted fuzzy AD calculations are made and the weights which are calculated in fuzzy AHP are taken into account. The results in Tables 10 and 11 are obtained.

Results of weighted axiomatic design show that the alternative "Arnavutköy" for the European Side of Istanbul and the alternative "Sultanbeyli" for the Asian Side of Istanbul are selected as the new garage locations because they have the minimum information contents.

4.1. ADSolver. Solving AD manually requires a lot of manual calculation. Thus an application called ADSolver was developed by authors. ADSolver was developed using $\mathrm{AD}$ algorithms on .net framework 3.5 and MSSQL 2008 Server Database. ADSolver includes additional properties to solve both Crisp and Fuzzy Axiomatic Design problems. If the weights of criteria are different or equal, ADSolver can be 
TABLE 3: The description of the criteria.

\begin{tabular}{|c|c|c|}
\hline Main criteria & Subcriteria & Description \\
\hline \multirow{4}{*}{ Cost-C1 } & C11-Investment cost & The total cost that is necessary for setting up the garage \\
\hline & $\begin{array}{l}\text { C12-Spare parts } \\
\text { transportation cost }\end{array}$ & The cost to transfer the spare parts from their suppliers to the garages \\
\hline & C13-Vehicle transport cost & $\begin{array}{l}\text { The cost that occurs when a bus travels without passengers to go to } \\
\text { the garage or to the start of the lines }\end{array}$ \\
\hline & C14-Operation cost & The total maintenance, cleaning, and other operations' cost \\
\hline \multirow[b]{2}{*}{ Infrastructure- $-\mathrm{C} 2$} & C21-Municipality services & Electric, water, and gas requirements supply from municipality \\
\hline & $\begin{array}{l}\text { C22-Technological } \\
\text { infrastructure }\end{array}$ & The infrastructure for telecommunication and internet supply \\
\hline \multirow{4}{*}{$\begin{array}{l}\text { Social and economic } \\
\text { structure-C3 }\end{array}$} & C31-Population structure & The density of the population in the regions \\
\hline & $\begin{array}{l}\text { C32-Urbanization of the } \\
\text { region }\end{array}$ & The immigration to the region and the population increase rate \\
\hline & $\begin{array}{l}\text { C33-Neighborhood } \\
\text { response }\end{array}$ & The response of the neighborhood when a new garage is set up \\
\hline & $\begin{array}{l}\text { C34-Behavior of the } \\
\text { passengers }\end{array}$ & $\begin{array}{l}\text { The satisfaction degree of the passengers who live around the new } \\
\text { garage }\end{array}$ \\
\hline \multirow[b]{2}{*}{ Macro factors-C4 } & C41-Government policy & The taxes and incentives \\
\hline & $\begin{array}{l}\text { C42-Reconstruction and } \\
\text { building plans }\end{array}$ & The features of the garage building \\
\hline \multirow{3}{*}{$\begin{array}{l}\text { Environmental } \\
\text { factors-C5 }\end{array}$} & $\begin{array}{l}\text { C51-Effects on the open } \\
\text { land }\end{array}$ & The effect of the new garage on the social/urban life \\
\hline & $\begin{array}{l}\text { C52-Convenience of the } \\
\text { land }\end{array}$ & The grade of the land, stream bed situation, and earthquake risk \\
\hline & $\begin{array}{l}\text { C53-Effect on people's } \\
\text { health }\end{array}$ & $\begin{array}{l}\text { The effect of the new garage on human health because of the exhaust, } \\
\text { dust, smell, and so forth }\end{array}$ \\
\hline \multirow{3}{*}{ Accessibility-C6 } & $\begin{array}{l}\text { C61-Proximity to } \\
\text { common service areas }\end{array}$ & $\begin{array}{l}\text { The proximity of the new garage to the common service areas is } \\
\text { important to decrease the dead kilometers }\end{array}$ \\
\hline & $\begin{array}{l}\text { C62-Proximity to the } \\
\text { other garages }\end{array}$ & $\begin{array}{l}\text { The proximity of the new garage to the other garages is important to } \\
\text { take service when a problem occurred in the new garage }\end{array}$ \\
\hline & $\begin{array}{l}\text { C63-Proximity to the } \\
\text { main roads }\end{array}$ & $\begin{array}{l}\text { The proximity to the main roads is important to decrease the spare } \\
\text { parts transportation cost and vehicle transport cost }\end{array}$ \\
\hline
\end{tabular}

TABLE 4: The main criteria of pairwise comparison matrix.

\begin{tabular}{cccccccccccccccccccc}
\hline & \multicolumn{3}{c}{$\mathrm{C} 1$} & \multicolumn{3}{c}{$\mathrm{C} 2$} & \multicolumn{3}{c}{$\mathrm{C} 3$} & \multicolumn{3}{c}{ C4 } & \multicolumn{3}{c}{ C5 } \\
\hline C1 & $(1.00$ & 1 & $1.00)$ & $(0.25$ & 0.33 & $0.50)$ & $(2.00$ & 3 & $4.00)$ & $(0.25$ & 0.33 & $0.50)$ & $(0.33$ & 0.5 & $1.00)$ & $(0.20$ & 0.25 & $0.33)$ \\
C2 & $(2.00$ & 3 & $4.00)$ & $(1.00$ & 1 & $1.00)$ & $(4.00$ & 5 & $6.00)$ & $(4.00$ & 5 & $6.00)$ & $(6.00$ & 7 & $8.00)$ & $(0.20$ & 0.25 & $0.33)$ \\
C3 & $(0.25$ & 0.33 & $0.50)$ & $(0.17$ & 0.2 & $0.25)$ & $(1.00$ & 1 & $1.00)$ & $(1.00$ & 1 & $2.00)$ & $(0.25$ & 0.33 & $0.50)$ & $(0.25$ & 0.33 & $0.50)$ \\
C4 & $(2.00$ & 3 & $4.00)$ & $(0.17$ & 0.2 & $0.25)$ & $(0.50$ & 1 & $1.00)$ & $(1.00$ & 1 & $1.00)$ & $(0.25$ & 0.33 & $0.50)$ & $(0.20$ & 0.25 & $0.33)$ \\
C5 & $(2.00$ & 3 & $4.00)$ & $(0.13$ & 0.14 & $0.17)$ & $(2.00$ & 3 & $4.00)$ & $(2.00$ & 3 & $4.00)$ & $(1.00$ & 1 & $1.00)$ & $(0.20$ & 0.25 & $0.33)$ \\
C6 & $(3.00$ & 4 & $5.00)$ & $(3.00$ & 4 & $5.00)$ & $(2.00$ & 3 & $4.00)$ & $(3.00$ & 4 & $5.00)$ & $(3.00$ & 4 & $5.00)$ & $(1.00$ & 1 & $1.00)$ \\
\hline
\end{tabular}

used to solve the problem. The pseudocode of ADSolver is given in Pseudocode 1.

4.1.1. Algorithms of ADSolver. In this program, the weighted fuzzy axiomatic design principles have been used because, after the meetings with experts in IETT, it is considered that all evaluation criteria do not have the same importance weights. When we solve the problem by ADSolver, the new garage locations are again Arnavutköy and Sultanbeyli.
The application steps of ADSolver are given below.

Step 1. In the first step each alternative is added to ADSolver program on Alternatives Tab.

Step 2. In the second step both main and subcriteria are added to ADSolver program on Attribute Tab (Figure 6).

Step 3. Design range of the each subcriterion is added as possible form for the criteria on Design Range Tab (Figure 7). 


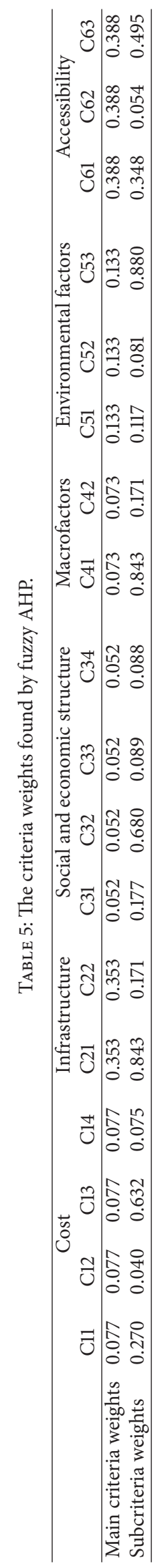


TABLE 6: The system and design range for European Side of Istanbul.

\begin{tabular}{|c|c|c|c|c|}
\hline \multicolumn{5}{|c|}{ European Side alternatives } \\
\hline & Beylikdüzü & $\begin{array}{l}\text { System range } \\
\text { Arnavutköy }\end{array}$ & Silivri & Design range \\
\hline $\mathrm{C} 11$ & $55,000,000-65,000,000$ & $34,000,000-35,000,000$ & $40,000,000-45,000,000$ & $30,000,00-60,000,000$ \\
\hline $\mathrm{C} 12$ & $250,000-300,000$ & $175,000-200,000$ & $375,000-450,000$ & $150,000-400,000$ \\
\hline $\mathrm{C} 13$ & $1,250,000-1,500,000$ & $800,000-1,000,000$ & $2,300,000-2,500,000$ & $900,000-2,400,000$ \\
\hline $\mathrm{C} 14$ & $4,700,000-4,950,000$ & $7,200,000-7,425,000$ & $12,000,000-12,375,000$ & $4,500,000-12,250,000$ \\
\hline $\mathrm{C} 21$ & $8,11,14$ & $8,11,14$ & $8,11,14$ & minimum 12 \\
\hline $\mathrm{C} 22$ & $4,7,10$ & $8,11,14$ & $4,7,10$ & minimum 8 \\
\hline $\mathrm{C} 31$ & $4,7,10$ & $8,11,14$ & $8,11,14$ & minimum 8 \\
\hline C32 & $4,7,10$ & $12,15,18$ & $8,11,14$ & minimum 8 \\
\hline $\mathrm{C} 33$ & $12,15,18$ & $8,11,14$ & $8,11,14$ & minimum 8 \\
\hline $\mathrm{C} 34$ & $8,11,14$ & $8,11,14$ & $8,11,14$ & minimum 4 \\
\hline C41 & $8,11,14$ & $8,11,14$ & $12,15,18$ & minimum 12 \\
\hline C42 & $4,7,10$ & $12,15,18$ & $12,15,18$ & minimum 8 \\
\hline C51 & $4,7,10$ & $8,11,14$ & $8,11,14$ & minimum 8 \\
\hline C52 & $4,7,10$ & $12,15,18$ & $8,11,14$ & minimum 8 \\
\hline C53 & $4,7,10$ & $8,11,14$ & $8,11,14$ & minimum 8 \\
\hline C61 & $8,11,14$ & $8,11,14$ & $4,7,10$ & minimum 8 \\
\hline C62 & $8,11,14$ & $12,15,18$ & $4,7,10$ & minimum 8 \\
\hline C63 & $8,11,14$ & $8,11,14$ & $8,11,14$ & minimum 8 \\
\hline
\end{tabular}

TABLE 7: The system and design range for Asian Side of Istanbul.

\begin{tabular}{|c|c|c|c|c|}
\hline \multicolumn{5}{|c|}{ Asian Side alternatives } \\
\hline & \multicolumn{3}{|c|}{ System range } & \multirow{2}{*}{ Design range } \\
\hline & Pendik & Sultanbeyli & Tuzla & \\
\hline $\mathrm{C} 11$ & $50,000,000-60,000,000$ & $30,000,000-31,000,000$ & $39,000,000-43,000,000$ & $30,000,00-60,000,000$ \\
\hline $\mathrm{C} 12$ & $50,000-55,000$ & $55,000-75,000$ & $32,000-37,000$ & $30,000-80,000$ \\
\hline $\mathrm{C} 13$ & $750,000-950,000$ & $780,000-1,000,000$ & $1,000,000-1,150,000$ & $700,000-1,300,000$ \\
\hline $\mathrm{C} 14$ & $4,700,000-4,950,000$ & $5,800,000-600,000$ & $8,800,000-9,000,000$ & $4,500,000-10,000,000$ \\
\hline $\mathrm{C} 21$ & $8,11,14$ & $8,11,14$ & $8,11,14$ & minimum 12 \\
\hline $\mathrm{C} 22$ & $8,11,14$ & $4,7,10$ & $4,7,10$ & minimum 8 \\
\hline C31 & $4,7,10$ & $4,7,10$ & $8,11,14$ & minimum 8 \\
\hline C32 & $8,11,14$ & $12,15,18$ & $12,15,18$ & minimum 8 \\
\hline $\mathrm{C} 33$ & $4,7,10$ & $12,15,18$ & $8,11,14$ & minimum 8 \\
\hline $\mathrm{C} 34$ & $8,11,14$ & $8,11,14$ & $8,11,14$ & minimum 4 \\
\hline C41 & $8,11,14$ & $12,15,18$ & $12,15,18$ & minimum 12 \\
\hline $\mathrm{C} 42$ & $8,11,14$ & $12,15,18$ & $4,7,10$ & minimum 8 \\
\hline C51 & $4,7,10$ & $8,11,14$ & $8,11,14$ & minimum 8 \\
\hline C52 & $8,11,14$ & $12,15,18$ & $4,7,10$ & minimum 8 \\
\hline C53 & $4,7,10$ & $8,11,14$ & $8,11,14$ & minimum 8 \\
\hline C61 & $8,11,14$ & $8,11,14$ & $4,7,10$ & minimum 8 \\
\hline C62 & $4,7,10$ & $12,15,18$ & $4,7,10$ & minimum 8 \\
\hline C63 & $12,15,18$ & $8,11,14$ & $12,15,18$ & minimum 8 \\
\hline
\end{tabular}

TABLE 8: Unit Index for unweighted information contents for European Side of Istanbul.

\begin{tabular}{lccccccr}
\hline Alternatives & $I_{1}$ & $I_{2}$ & $I_{3}$ & $I_{4}$ & $I_{5}$ & $I_{6}$ \\
\hline Beylikdüzü & 0.250 & 4.407 & 3.354 & 4.407 & 5.492 & 2.322 \\
Arnavutköy & 0.250 & 2.822 & 1.769 & 2.822 & 1.980 & 1.980 & $11.622^{*}$ \\
Silivri & 0.792 & 4.407 & 2.025 & 1.292 & 1.980 & 4.435 \\
\hline
\end{tabular}

${ }^{*}$ refers the most appropriate alternatives for the location selection. 
TABle 9: Unit Index for unweighted information contents for Asian Side of Istanbul.

\begin{tabular}{lccccccc}
\hline Alternatives & $I_{1}$ & $I_{2}$ & $I_{3}$ & $I_{4}$ & $I_{5}$ & $I_{6}$ & Total \\
\hline Pendik & 0.000 & 2.822 & 3.610 & 2.822 & 4.435 & 3.036 & 16.726 \\
Sultanbeyli & 0.000 & 4.407 & 2.305 & 1.292 & 1.980 & 1.980 & $11.964^{*}$ \\
Tuzla & 0.000 & 4.407 & 1.769 & 3.391 & 3.379 & 4.093 \\
\hline
\end{tabular}

${ }^{*}$ refers the most appropriate alternatives for the location selection.

TABLE 10: Unit Index for weighted information contents for European Side of Istanbul.

\begin{tabular}{lccccccc}
\hline & $I_{1}$ & $I_{2}$ & $I_{3}$ & $I_{4}$ & $I_{5}$ & $I_{6}$ & Total \\
\hline Beylikdüzü & 0.000 & 1.287 & 1.026 & 1.054 & 1.116 & 1.108 & 5.591 \\
Arnavutköy & 0.000 & 1.266 & 1.005 & 1.050 & 1.047 & 1.104 & $5.473^{*}$ \\
Silivri & 0.000 & 1.287 & 1.012 & 1.010 & 1.046 & 1.163 \\
\hline
\end{tabular}

${ }^{*}$ refers the most appropriate alternatives for the location selection.

TABLE 11: Unit Index for weighted information contents for Asian Side of Istanbul.

\begin{tabular}{lccccccc}
\hline & $I_{1}$ & $I_{2}$ & $I_{3}$ & $I_{4}$ & $I_{5}$ & $I_{6}$ & Total \\
\hline Pendik & 0.0 & 1.266 & 1.015 & 1.050 & 1.115 & 1.070 & 5.516 \\
Sultanbeyli & 0.0 & 1.287 & 1.007 & 1.010 & 1.047 & 1.104 & $5.455^{*}$ \\
Tuzla & 0.0 & 1.287 & 1.005 & 1.019 & 1.051 & 1.123 \\
\hline
\end{tabular}

${ }^{*}$ refers the most appropriate alternatives for the location selection.

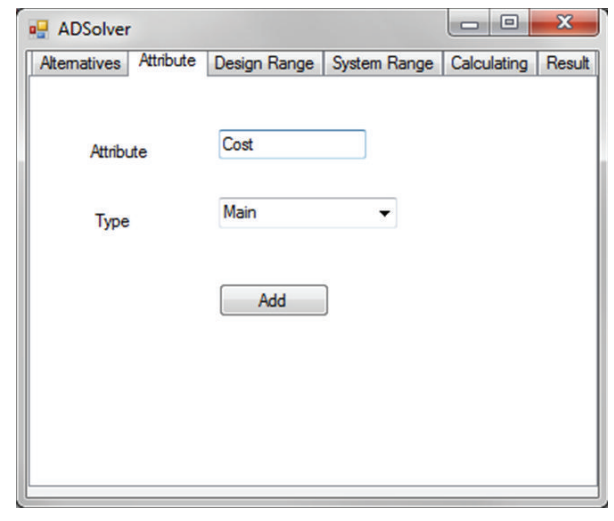

FIGURE 6: Entering the main and subcriteria.

Step 4. System range of each subcriterion is added as possible form for the criteria on Design Range Tab (Figure 8).

Step 5. Then it is decided if the type of criteria is weighted or unweighted. If the type of criteria is weighted, the weight of each main criterion and subcriterion is added to ADSolver program on Calculating Tab. After all criteria are added to program, the Calculate button is clicked. The coded algorithm is run automatically and the result of the problem is listed on the next tab (Figures 9 and 10).

4.2. Scenario Analysis. Scenario analysis is conducted to see the results when some parameters are changed. In this study, scenario analysis has been made by changing the weights of main criteria and subcriteria in seven different scenarios.

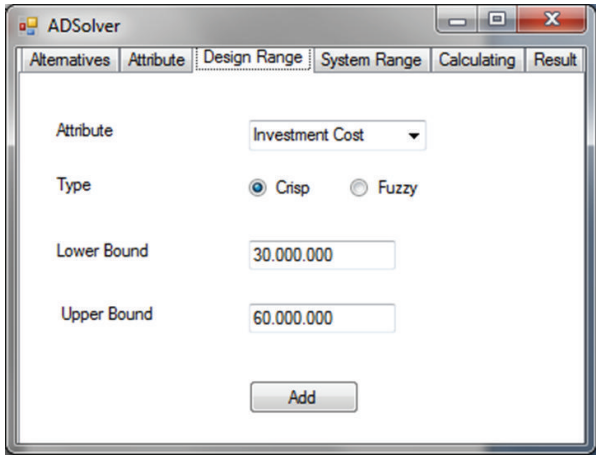

FIGURE 7: Entering the design ranges.

In current application, the criteria weights are handled by fuzzy AHP. In each scenario, current weight of a chosen main criterion is increased and the remaining criteria are fixed to their current values. Then new weights are normalized. For example, in scenario 1 , the current weight of "Cost" main criterion is increased 25 times and the changed weights of the criteria are normalized, as shown in Table 12. The result of the weighted fuzzy AD brought "Beylikdüzü" to the first order (Table 13). Also the definitions of other scenarios and the obtained results are shown in Tables 12 and 13, respectively.

\section{Conclusion}

Istanbul is a growing city and the land use is very important in terms of the city master plans. Considering this reality, we determined probable bus garage locations by taking the opinions of IETT authorities. The main contribution to the literature is applying fuzzy $\mathrm{AD}$ and weighted fuzzy $\mathrm{AD}$ 
Input data: alternative, mainCriteria, subCriteria, designRange, systemRange, typeOfAD;

For $i=1$ to number of alternatives

Insert name of alternative;

End For;

For $j=1$ to number of mainAttributes

Insert name of mainAttribute;

For $k=1$ to number of mainAttributes

Insert name of subAttribute;

Insert designRange values for subAttribute;

Insert systemRange values for subAttribute;

If typeOfAD $==$ weighted then

End If;

Insert weight of subAttribute;

End For;

If typeOfAD $==$ weighted then

End If;

Insert weight of mainAttribute;

End For;

For $m=1$ to number of mainAttributes

For $n=1$ to number of subAttributes

Set $I=\log _{2}$ (system area for subAttribute/common area for subAttribute);

If typeOfAD $==$ weighted then

Set Information Content of

SubAttribute $=$ weight of subAttribute $* I$;

End If;

Set Total Information Content of mainAttribute $=+$ Information Content of SubAttribute;

End For;

If typeOfAD $==$ weighted then

Set Information Content of

mainAttribute $=$ weight of mainAttribute $*$ Total Information Content of mainAttribute;

End If;

End For;

For $o=1$ to number of alternatives

Choose of the alternative has lowest Information Content;

End For;

End.

Pseudocode 1: Program ADSolver.

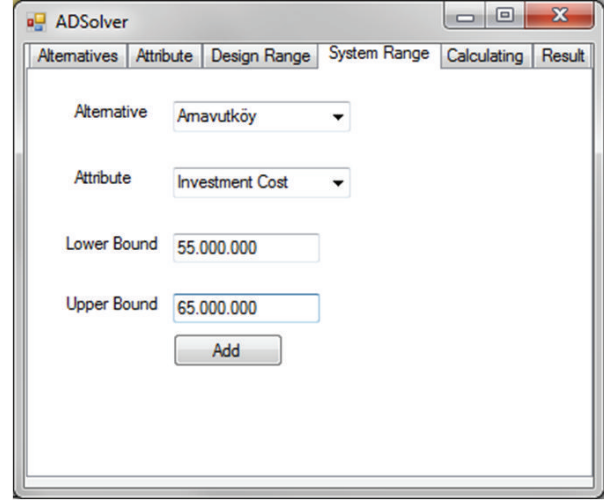

FIGURE 8: Entering the system ranges.

integrating with fuzzy AHP to select the best alternative garage location for the biggest city in Turkey, Istanbul.

The aim of using $\mathrm{AD}$ is taking into account the design ranges for all attributes. Besides, making the evaluation by

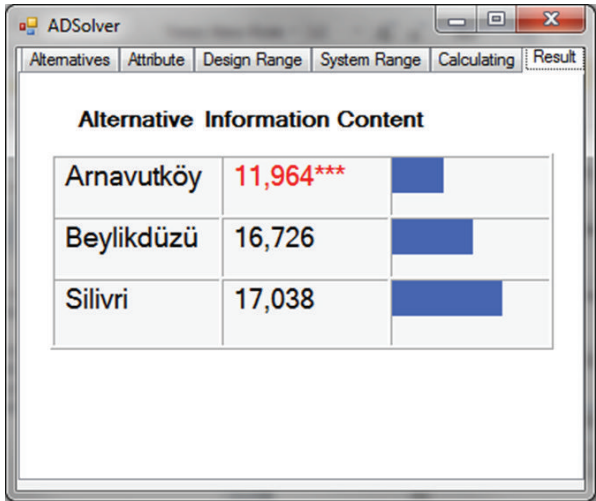

FIGURE 9: Solution of the ADSolver for unweighted AD problem.

using linguistic terms and transforming them into fuzzy numbers is an easier way for decision makers. It helps the decision maker to select the most appropriate alternative that is suitable with his/her design features. This is 
TABLE 12: The weights of each criterion for each scenario.

\begin{tabular}{lcccccccc}
\hline Scenario & Definition & $W 1$ & $W 2$ & $W 3$ & $W 4$ & $W 5$ & $W 6$ & Total \\
\hline 1 & $W 1$ is increased 25 times & 0.606 & 0.139 & 0.02 & 0.029 & 0.053 & 0.153 & 1.000 \\
2 & $W 3$ is increased 10 times & 0.05 & 0.229 & 0.337 & 0.047 & 0.086 & 0.251 & 1.000 \\
3 & $W 4$ is increased 5 times & 0.056 & 0.258 & 0.038 & 0.267 & 0.098 & 0.284 & 1.000 \\
4 & $W 5$ is increased 40 times & 0.012 & 0.056 & 0.008 & 0.012 & 0.85 & 0.062 & 1.000 \\
5 & $W 2$ is increased 10 times & 0.029 & 0.134 & 0.02 & 0.028 & 0.051 & 0.738 & 1.000 \\
6 & $W 3$ is increased 20 times & 0.037 & 0.171 & 0.504 & 0.035 & 0.065 & 0.188 & 1.000 \\
7 & $W 6$ is increased 5 times & 0.029 & 0.134 & 0.02 & 0.028 & 0.051 & 0.738 & 1.000 \\
\hline
\end{tabular}

TABLE 13: The results of scenarios for both sides of Istanbul.

\begin{tabular}{|c|c|c|c|c|c|c|c|c|}
\hline \multicolumn{5}{|c|}{ European Side } & \multicolumn{4}{|c|}{ Asian Side } \\
\hline Alternatives & Scenario 1 & Scenario 2 & Scenario 3 & Scenario 4 & Alternatives & Scenario 5 & Scenario 6 & Scenario 7 \\
\hline Beylikdüzü & $5.233^{*}$ & $5.379^{*}$ & 5.593 & 6.086 & Pendik & $5.298^{*}$ & 5.385 & $6.035^{*}$ \\
\hline Arnavutköy & 5.255 & 5.393 & 5.497 & 5.400 & Sultanbeyli & 5.332 & 5.277 & 6.138 \\
\hline Silivri & 5.425 & 5.416 & $5.397^{*}$ & $5.399^{*}$ & Tuzla & 5.375 & $5.275^{*}$ & 6.180 \\
\hline
\end{tabular}

${ }^{*}$ refers the most appropriate alternatives for the location selection.

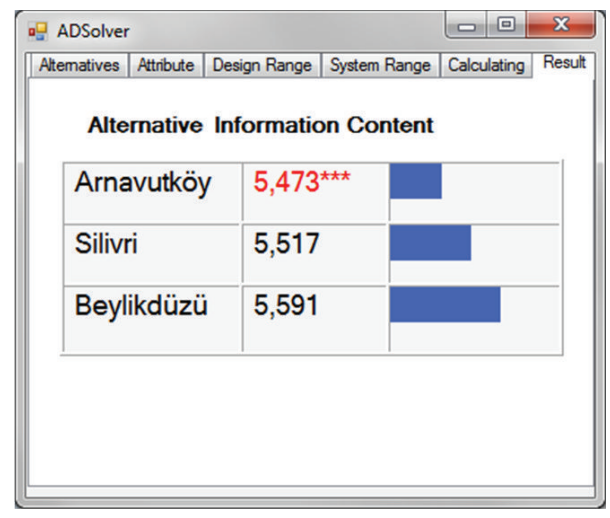

FIGURE 10: Solution of the ADSolver for weighted AD problem.

the strength of the proposed method over the existing ones. $\mathrm{AD}$ approach uses design ranges for each criterion, determined by the designer. Thus, the alternatives, which ensure the design ranges, are selected in $\mathrm{AD}$ approach. However, other multicriteria methods select the alternatives that meet the criteria at their best levels. The AD approach also differs from many other existing methods from the point of the rejection of an alternative when it does not meet the design range of any criterion.

By taking these advantages, fuzzy $\mathrm{AD}$ is applied and Arnavutköy for European Side and Sultanbeyli for Asian Side of Istanbul are selected. In weighted fuzzy AD the same garage locations are selected. Even if the obtained results are similar, the weights of the criteria generally very important in terms of the decision makers. In scenario analysis, effects of the criteria weights on the results are depicted.

After manual calculations, we solved our problem by ADSolver which solves the problem directly in terms of the user. This computer program is very useful for the decision makers and it increases the applicability of the approach. In future studies, the combined transportation systems in different modes can be adapted to the problem. The effect of this enhancement will be an increase in the number of criteria. Under this circumstance solving the problem by ADSolver will be more significant.

\section{Conflict of Interests}

The authors declare that there is no conflict of interests regarding the publication of this paper.

\section{Acknowledgment}

The authors would like to express their thanks and appreciation to IETT employees and managers for their contributions and attention on defining and evaluating the problem.

\section{References}

[1] B. Özel and B. Özyörük, "Supplier selection with fuzzy axiomatic design," Journal of the Faculty of Engineering and Architecture of Gazi University, vol. 22, no. 3, pp. 415-423, 2007.

[2] A. M. Gonçalves-Coelho and A. J. F. Mourão, "Axiomatic design as support for decision-making in a design for manufacturing context: a case study," International Journal of Production Economics, vol. 109, no. 1-2, pp. 81-89, 2007.

[3] O. Kulak and C. Kahraman, "Fuzzy multi-attribute selection among transportation companies using axiomatic design and analytic hierarchy process," Information Sciences, vol. 170, no. 2-4, pp. 191-210, 2005.

[4] EN 13816, "European Committee for Standardization," Brussels, Belgium, 2002, http://www.transportbenchmarks.eu/.

[5] The IETT website, http://www.iett.gov.tr/.

[6] E. Y1lmaz, "Axiomatic design of urban public transportation systems," Uludağ University Journal of the Faculty of Engineering and Architecture, vol. 11, no. 1, pp. 9-26, 2006.

[7] S. J. Kim, N. P. Suh, and S. G. Kim, "Design of software systems based on axiomatic design," Robotics and Computer Integrated Manufacturing, vol. 8, no. 4, pp. 243-255, 1991. 
[8] N. P. Suh, "Designing-in of quality through axiomatic design," Microelectronics Reliability, vol. 37, no. 3, pp. 538-539, 1997.

[9] N. P. Suh, D. S. Cochran, and P. C. Lima, "Manufacturing system design," CIRP Annals_Manufacturing Technology, vol. 47, no. 2, pp. 627-639, 1998.

[10] B. Babic, "Axiomatic design of flexible manufacturing systems," International Journal of Production Research, vol. 37, no. 5, pp. 1159-1173, 1999.

[11] O. Kulak and M. B. Durmuşoğlu, "A complete cellular manufacturing system design methodology based on axiomatic design principles," ITO Engineering Journal, vol. 3, no. 6, pp. 33-46, 2004.

[12] O. Kulak, M. B. Durmuşoǧlu, and C. Kahraman, "Fuzzy multiattribute equipment selection based on information axiom," Journal of Materials Processing Technology, vol. 169, no. 3, pp. 337-345, 2005.

[13] C. Kahraman, I. Kaya, and S. Cebi, "A comparative analysis for multiattribute selection among renewable energy alternatives using fuzzy axiomatic design and fuzzy analytic hierarchy process," Energy, vol. 34, no. 10, pp. 1603-1616, 2009.

[14] T. Kaya and C. Kahraman, "An integrated fuzzy AHP-ELECTRE methodology for environmental impact assessment," Expert Systems with Applications, vol. 38, no. 7, pp. 8553-8562, 2011.

[15] M. Celik, S. Cebi, C. Kahraman, and I. D. Er, "Application of axiomatic design and TOPSIS methodologies under fuzzy environment for proposing competitive strategies on Turkish container ports in maritime transportation network," Expert Systems with Applications, vol. 36, no. 3, pp. 4541-4557, 2009.

[16] S. Cebi and C. Kahraman, "Developing a group decision support system based on fuzzy information axiom," KnowledgeBased Systems, vol. 23, no. 1, pp. 3-16, 2010.

[17] M. Celik, C. Kahraman, S. Cebi, and I. D. Er, "Fuzzy axiomatic design-based performance evaluation model for docking facilities in shipbuilding industry: the case of Turkish shipyards," Expert Systems with Applications, vol. 36, no. 1, pp. 599-615, 2009.

[18] T. Özcan, N. Çelebi, and Ş. Esnaf, "Comparative analysis of multi-criteria decision making methodologies and implementation of a warehouse location selection problem," Expert Systems with Applications, vol. 38, no. 8, pp. 9773-9779, 2011.

[19] A. Awasthi, S. S. Chauhan, and S. K. Goyal, "A multi-criteria decision making approach for location planning for urban distribution centers under uncertainty," Mathematical and Computer Modelling, vol. 53, no. 1-2, pp. 98-109, 2011.

[20] Y. Li, X. Liu, and Y. Chen, "Selection of logistics center location using Axiomatic Fuzzy Set and TOPSIS methodology in logistics management," Expert Systems with Applications, vol. 38, no. 6, pp. 7901-7908, 2011.

[21] Y. Kayikci, "A conceptual model for intermodal freight logistics centre location decisions," Procedia Social and Behavioral Sciences, vol. 2, no. 3, pp. 6297-6311, 2010.

[22] M. S. Kuo, "Optimal location selection for an international distribution center by using a new hybrid method," Expert Systems with Applications, vol. 38, no. 6, pp. 7208-7221, 2011.

[23] Ö. N. Alp, N. Demirtaş, H. Baraçl, and U. R. Tuzkaya, in 15th International Research/Expert Conference: Trends in the Development of Machinery and Associated Technology (TMT '11), Prague, Czech Republic, September 2011.

[24] S.-Y. Chou, Y.-H. Chang, and C.-Y. Shen, "A fuzzy simple additive weighting system under group decision-making for facility location selection with objective/subjective attributes,"
European Journal of Operational Research, vol. 189, no. 1, pp.132145, 2008.

[25] C. Kahraman, D. Ruan, and I. Doğan, "Fuzzy group decisionmaking for facility location selection," Information Sciences, vol. 157, no. 1-4, pp. 135-153, 2003.

[26] J. Ma, J. Lu, and G. Zhang, "Decider: a fuzzy multi-criteria group decision support system," Knowledge-Based Systems, vol. 23, no. 1, pp. 23-31, 2010.

[27] G. Zhang and J. Lu, "An integrated group decision-making method dealing with fuzzy preferences for alternatives and individual judgments for selection criteria," Group Decision and Negotiation, vol. 12, no. 6, pp. 501-515, 2003.

[28] T. Chen, "A collaborative fuzzy-neural approach for longterm load forecasting in Taiwan," Computers and Industrial Engineering, vol. 63, no. 3, pp. 663-670, 2012.

[29] U. Cebeci, "Fuzzy AHP-based decision support system for selecting ERP systems in textile industry by using balanced scorecard," Expert Systems with Applications, vol. 36, no. 5, pp. 8900-8909, 2009.

[30] T.-Y. Hsieh, S.-T. Lu, and G.-H. Tzeng, "Fuzzy MCDM approach for planning and design tenders selection in public office buildings," International Journal of Project Management, vol. 22, no. 7, pp. 573-584, 2004.

[31] C. Kahraman and S. Çebi, "A new multi-attribute decision making method: hierarchical fuzzy axiomatic design," Expert Systems with Applications, vol. 36, no. 3, pp. 4848-4861, 2009.

[32] O. Kulak, "A decision support system for fuzzy multi-attribute selection of material handling equipments," Expert Systems with Applications, vol. 29, no. 2, pp. 310-319, 2005. 


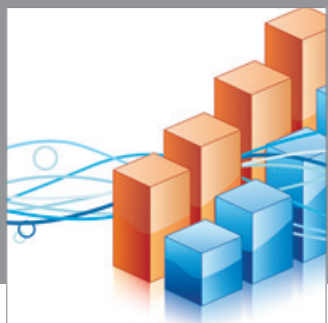

Advances in

Operations Research

mansans

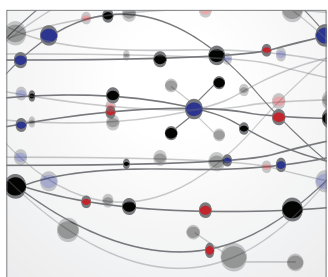

The Scientific World Journal
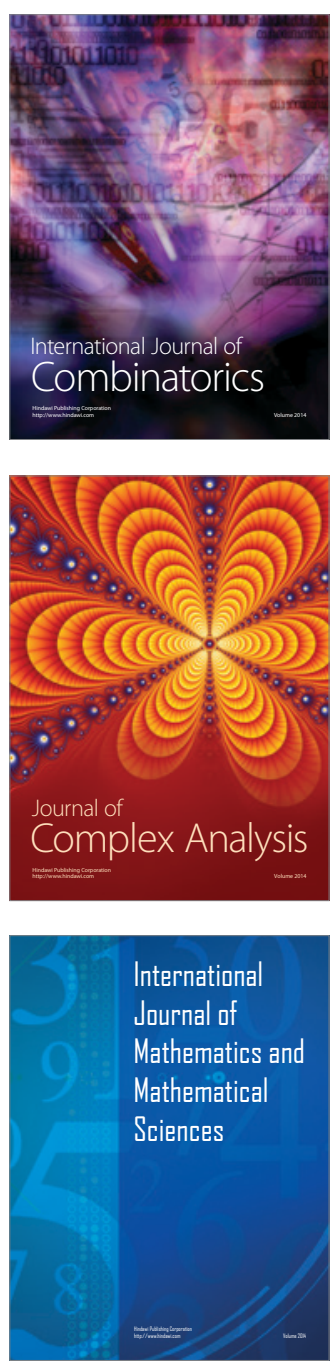
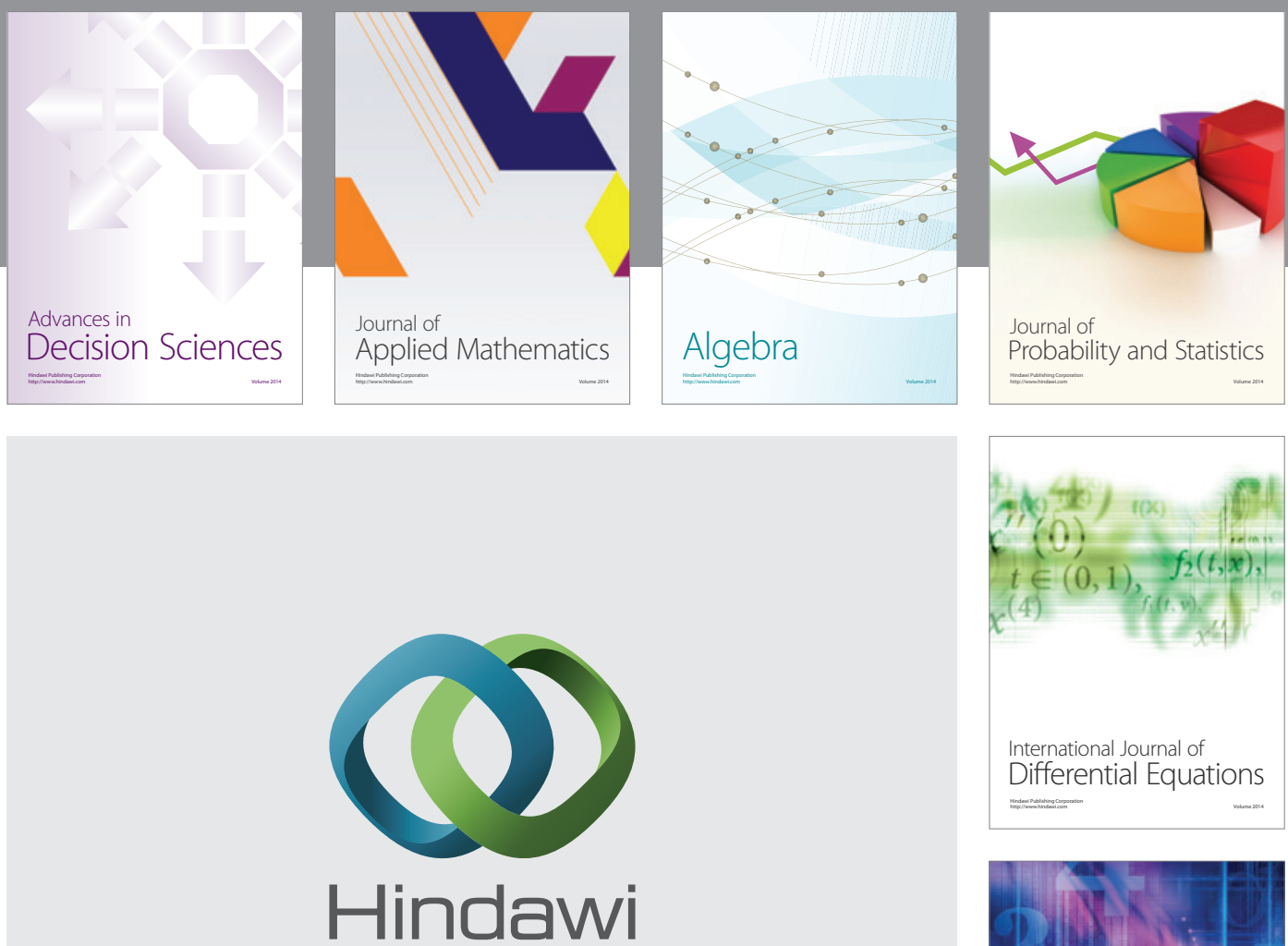

Submit your manuscripts at http://www.hindawi.com
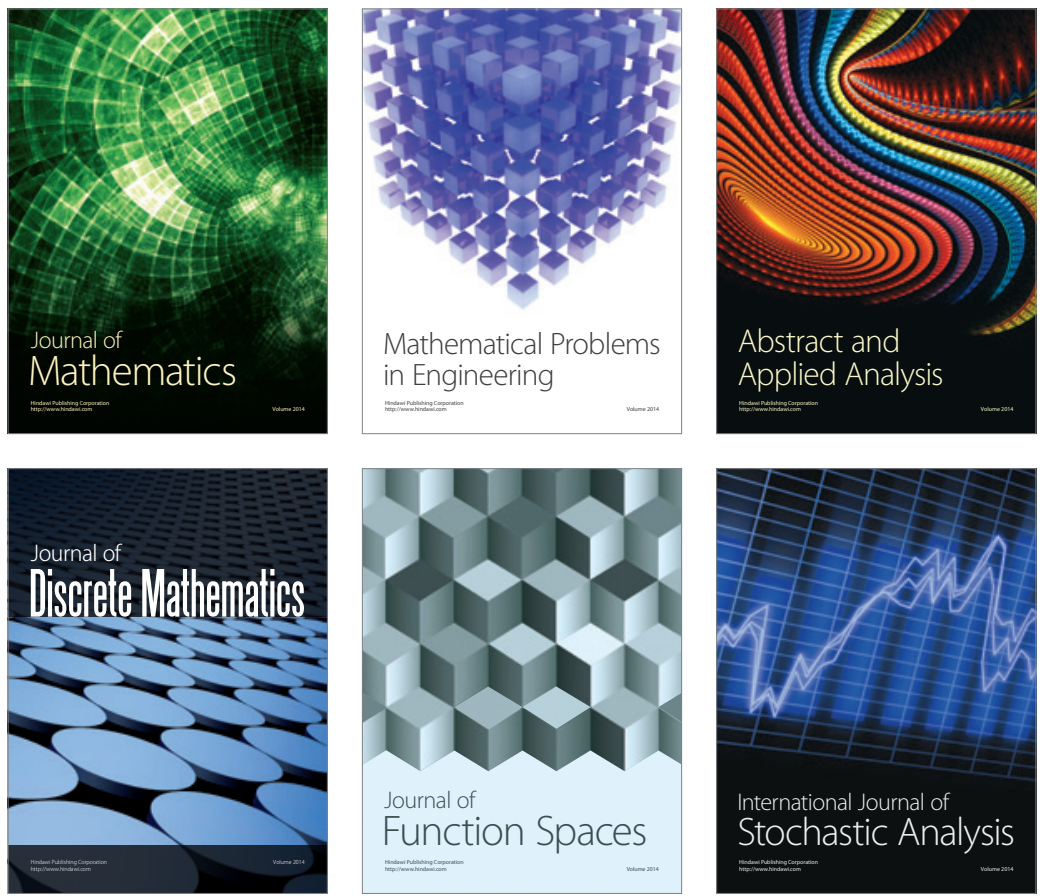

Journal of

Function Spaces

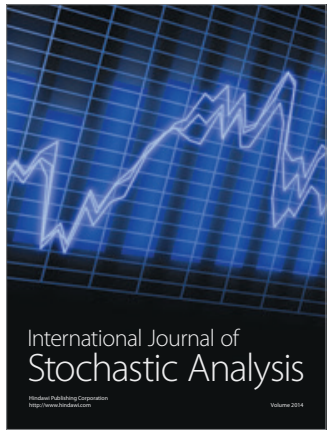

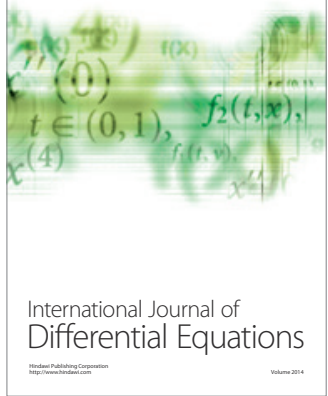
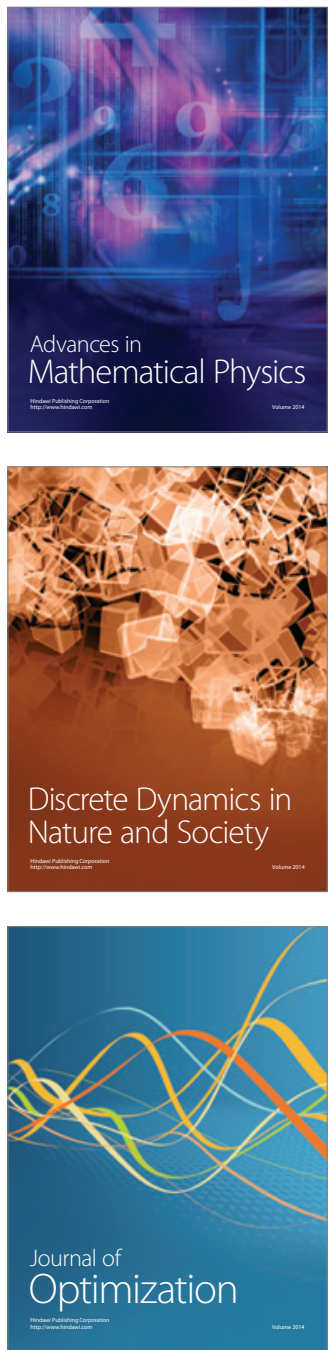